\title{
Social capital of venture capitalists and start-up funding
}

\author{
Oliver T. Alexy $\cdot$ Joern H. Block • \\ Philipp Sandner • Anne L. J. Ter Wal
}

Accepted: 25 February 2011/Published online: 13 April 2011

(C) The Author(s) 2011. This article is published with open access at Springerlink.com

\begin{abstract}
How does the social capital of venture capitalists (VCs) affect the funding of start-ups? By building on the rich social capital literature, we hypothesize a positive effect of VCs' social capital, derived from past syndication, on the amount of money that start-ups receive. Specifically, we argue that both structural and relational aspects of VCs' social networks provide VCs with superior access to information about current investment objects and
\end{abstract}

An earlier version of this paper by the same authors appeared in Frontiers in Entrepreneurship Research, the Best Paper Proceedings of the Babson College Entrepreneurship Research Conference 2010.

O. T. Alexy · A. L. J. Ter Wal

Imperial College Business School, Tanaka Building, South Kensington Campus, London SW7 2AZ, UK

e-mail: o.alexy@imperial.ac.uk

A. L. J. Ter Wal

e-mail: a.terwal@imperial.ac.uk

J. H. Block $(\square)$

Centre for Advanced Small Business Economics, Erasmus

School of Economics, Erasmus Research Institute of

Management (ERIM), Erasmus University Rotterdam,

P.O. Box 1738, 3000 DR Rotterdam, The Netherlands

e-mail: block@ese.eur.nl

P. Sandner

Munich School of Management, Chair for Strategy and Organization, Technische Universität München (TUM), Munich, Germany

e-mail: philipp.sandner@tum.de opportunities to leverage them in the future, increasing their willingness to invest in these firms. Our empirical results, derived from a novel dataset containing more than 1,500 first funding rounds in the Internet and IT sector, strongly confirm our hypotheses. We discuss the implications of our findings for theories of venture capital and entrepreneurship, showing that the role and effect of $\mathrm{VCs}$ ' social capital on start-up firms may be more complex than previously argued in the literature.

Keywords Venture capital - Social capital . Start-ups · Social networks $\cdot$ Structural holes

JEL Classifications $\quad$ G24 $\cdot$ L26 $\cdot$ M13 $\cdot$ L26

\section{Introduction}

Venture capital investment plays a pivotal role in entrepreneurial processes. Aside from the capabilities and resources of the start-up and its founders (Burton et al. 2002; De Clercq et al. 2006), venture capital firms (VCs) ${ }^{1}$ arguably have the highest level of

\footnotetext{
${ }^{1}$ We understand that VCs are not the only source of funding for innovative start-ups. However, since they are the largest category of investors in our dataset, and, more generally, likely to be the most important and impactful source of funding for new ventures (De Clercq et al. 2006), we will use this term to also include corporate venture capitalists and business angels,
} 
influence in shaping and developing start-up firms (Audretsch and Thurik 2001; Hsu 2006). Simply put, VCs, often as a syndicate of several VCs rather than alone and with the goal of their own financial profit in mind (Lerner 1994; Wright and Lockett 2003), equip growth-oriented start-ups with essential resources to support them in their evolution and eventual success. In doing so, VCs impact on new ventures in two distinct ways: directly, by lending money (financial capital) and providing management skills (human capital) to the start-ups they fund, and indirectly, by giving them access to their network, thus taking on the role of information and resource brokers (social capital) (De Clercq et al. 2006; Dimov and Shepherd 2005; Pratch 2005; Sapienza et al. 1996).

Generally, social capital is receiving ever more attention in entrepreneurship research (Aldrich and Zimmer 1986; Dimov et al. 2007; Hoang and Antoncic 2003). However, studies on the role of social capital in entrepreneurship usually focus on the social capital of the entrepreneurs themselves. For example, the social capital of starting entrepreneurs has widely been acknowledged to play an important role in the evolution of firms and their eventual success (Brüderl and Preisendörfer 1998; Hallen 2008) by positively affecting access to information, reputation-building, and recognition of opportunities (Burton et al. 2002; Hsu 2004). On the contrary, the role of the social capital and social networks of the investing VCs takes a much less prominent position. Extant literature mainly looks at the social capital of VCs through the eyes of the start-up (Hallen 2008; Hsu 2004), and how it may benefit from being funded by a high-social capital VC (Hsu 2006; Pratch 2005).

In this paper, by building on the social capital literature (Burt 2005; Coleman 1988) we strive to expand this restricted view of the effect of VCs' social capital. Fundamentally, a strong social network of the VC should not only hold opportunities for the start-up, but also for the VCs themselves by granting them access to superior information about new ventures and the environmental conditions they face. For the pre-investment phase, VCs with higher social capital may have a better knowledge of the most promising firms currently looking for funding (Burt

Footnote 1 continued

and thus use it interchangeably with the more general term "investor."
2005). Regarding the post-investment phase, Pratch (2005) and Hsu (2006) both show that VCs actively try to improve the odds of success of their investment using their social capital, which they derive from the social networks in which they are embedded through syndication. Privileged access to information highlighting such opportunities should therefore lead to the VC either evaluating future cash flows of the venture more positively, or attributing them with lower risk (see Tyebjee and Bruno 1984 for how VCs valuate firms).

Consequently, we argue that the social capital of VCs should have direct and measurable effects on the funding decision they make. In doing so, we address Fitza et al. (2009)'s observation that the question of how exactly VCs' social capital affects the funding of new ventures still lacks systematic research. We maintain that, compared to VCs that do not have access to the above types of information, a highsocial-capital VC should have a higher willingness to invest into a specific venture in the present (than a low-social-capital VC) for the same share of ownership in the new venture, or to risk buying a larger share of ownership of a specific venture. In turn, startups that are being invested in by VCs with high social capital might, ceteris paribus, be able to raise significantly larger amounts of financial capital than ventures that are being invested in by VCs with lower levels of social capital.

To understand the effect that VCs' social capital has on the investments they make in start-ups, we follow Sorensen and Stuart's (2001) approach in constructing the social network through VC syndication (Hopp 2010): a link between a new venture and a $\mathrm{VC}$ exists when the VC invests in it. Thus, when multiple VCs syndicate their investment, they are also connected to each other through the shared investment object. According to Granovetter (1992), we further distinguish structural and relational aspects of social capital, paying attention to both the configuration of a VC's syndication network and the diversity of its partners. Both aspects should, through distinct mechanisms, give VCs access to information that is helpful to them both in the preand post-investment phase. We then regress the lagged structural and relational attributes of investors on the amount of funds that they invest into a certain start-up in its first funding round. As a data source, we employ a novel dataset obtained from the 
information provider CrunchBase (Block and Sandner 2009). Within this dataset of over 4,300 firms, 3,800 financial organizations, and 11,300 funding rounds, we focus on $\mathrm{VC}$ activity in the Internet sector, for which (almost) complete network data covering the last years are available. This allows us to derive longitudinal, valued, network-based structural and relational measures, while other work in this area often relies on cross-sectional, survey-based, positional measures (Hoang and Antoncic 2003).

Our findings allow us to make three contributions to the literature on entrepreneurship and venture capital. First, we show that VCs' structural position in syndication networks positively influences the amount of money they invest in start-ups. Specifically, structural embeddedness measured by the number of connections gives VCs access to more information, and the spanning of structural holes increases the likelihood that incoming information will be of unique value. Both effects positively impact VCs' willingness to invest in new firms. Second, we also find clear indications for the importance of relational attributes of VCs' syndication networks. In particular, contrary to the extant literature on venture capital that argues mainly in favor of network specialization, we show that arguments from the social capital literature promoting the positive effects of diversity amongst network partners also hold for the setting of VC syndication and their investment in start-ups. In addition, we highlight that network strategies emphasizing either diversity or similarity are preferential in their effect compared to hybrid approaches. Taken together, our results reemphasize the importance of social networks and social capital for entrepreneurship research and entrepreneurs alike. In particular, we show that the role of social capital in the $\mathrm{VC}$-venture relationship may be more complex than previously hypothesized.

\section{Theory and hypotheses}

Venture capital investment plays an essential role in the evolution and eventual success of new ventures. In addition to the capabilities and resources of the start-up and characteristics of its founders (Burton et al. 2002; Franke et al. 2006), VCs arguably have the highest level of influence in shaping and developing start-up firms (Audretsch and Thurik 2001; Hsu 2006). By investing in new ventures, often as a syndicate of several VCs rather than alone (Lerner 1994; Wright and Lockett 2003), VCs impact new ventures in several ways. Primarily and most obviously, VCs, expecting a high rate of return at high risk, lend financial capital to new firms so that these can compensate their often negative cash flows and fund their growth ambitions (De Clercq et al. 2006). Moreover, VCs can assist startups by providing human capital in the form of management skills, experience, and expertise (Dimov and Shepherd 2005). VCs can do so in several ways, such as by providing strategic advice and planning support, by taking a governance role on a board of directors, or-though somewhat less likely-by actively engaging in day-to-day operations (Lerner 1995; Sapienza et al. 1996).

In addition, VCs have social capital that the startups will seek to access. This social capital is derived from the (social) network of professionals, experts (e.g., for industry, market, technology, and law issues), and other VCs in which the VCs are embedded. In particular, VCs are strongly linked with each other through the joint investments they have made in the past (Bygrave 1987; Hopp 2010; Sorenson and Stuart 2001, 2008). Through the social networks arising from such past syndication, VCs both receive from and pass on to each other strategic information on current investment opportunities as well as future innovation and technological trends, in turn which helps them to reduce the uncertainty they face (Bygrave 1987, 1988). Specifically, depending on the amount of social capital they have, VCs will have access to more or less of such information, which they will then exploit to the advantage of the firms in their portfolio (Hsu 2006; Pratch 2005). Thus, any effect of social capital that VCs receive from their embeddedness in social networks should result from their superior access to high-quality information (about any type of resource) and their ability to use it to the benefit of the firms they (intend to) invest in.

A strong social network of its VCs thus provides the start-up with access to unique and valuable resources and future opportunities. However, VCs themselves may also directly benefit from the prospects of their own network when making investment decisions. In a nutshell, their social capital may allow VCs to benefit from having superior access to highquality information and thus increase their chances of 
identifying the most promising investment opportunities in the pre-investment phase, as well as foreseeing opportunities to add value to the venture after the investment has been made. Looking at the potential for pre-investment information arbitrage, VCs are competing against each other to identify and invest in the most promising new ventures (Bygrave 1987). High social capital should give a VC an advantage in spotting suitable candidates for investment (see Burt 2005; Granovetter 1985; Uzzi 1997) and also increase the likelihood that their bid is accepted (Hsu 2004). Subsequently, during the postinvestment phase, VCs can leverage their investment through value-adding involvement in their ventures "as related to perceiving and responding to opportunities and threats to increase the chances of success of the portfolio companies" (Dimov and Shepherd 2005, p. 5). High social capital should again increase the likelihood that a VC will become aware of such opportunities and threats (see Burt 2005; Coleman 1988). For example, a VC with high social capital may be aware of specific customer groups or complementary ideas in development stage that may useful to the start-up it is considering investing in (Bygrave 1988). For such a VC, therefore, the value of future cash flows it may receive from the start-up should increase, and the associated risk decrease, which should lead to a higher willingness to invest into the start-up at the present time (Tyebjee and Bruno 1984). On the one hand, this higher willingness to invest may be expressed by a higher willingness-to-pay for the same share of ownership in the new venture. On the other hand, it may be expressed by decreased risk-adversity, leading highsocial-capital VCs to invest more money into the same venture to buy a large portion of ownership. From the perspective of the start-up, this means that the total funds it can raise in one funding round should increase with the social capital of the investors that participate in it.

There are two sources of social capital, which, in distinct ways, will provide VCs with access to valuable information from their environment as we have described above, namely, the structural and relational aspects of the syndication network in which VCs are embedded. Structural aspects describe the configuration of the network, such as the number and intensity of connections a VC has with others (Uzzi 1997) and the position of the VC in the syndication network (Burt 2005). Relational aspects on the other hand focus on who one is connected with, including their (relative) characteristics (Flap and Völker 2004; Granovetter 1992). For example, whether I am central or not within a network is a structural characteristic; whether I am connected to people that are similar or dissimilar to me is a relational characteristic.

In the following, we will derive hypotheses for why and how structural and relational aspects of a VC's social networks facilitate access to superior information, thereby increasing a VC's willingness to invest in a start-up firm, and, consequently, the investment sum the new venture may collect in a funding round. In doing so, we build on Fleming et al. (2007, pp. 444-445) who note that "[most] research on the influence of brokerage has focused on purely structural explanations (...). Little research in the controversy has started from the premise that individuals have biographies and experiences and attributes that they bring to their brokered or cohesive collaborations." We thus follow more recent studies that pay increasing attention also to the relational characteristics of networks (Moran 2005; Reagans and McEvily 2003).

\subsection{Structural aspects and investment sum}

Due to the syndicative nature of the VC industry, most VCs make their investments in new start-ups jointly with other VCs (Lerner 1994; Wright and Lockett 2003). On the one hand, this may bring at least "another pair of eyes" to a deal, thus decreasing the likelihood of failed investments. At the same time, other VCs may contribute distinct competencies to the partnership that will increase the likelihood of venture success (for a discussion of these partly competing explanations, see Brander et al. 2002). On top of this, joint investments create ties between organizations through which information can be exchanged in the future, which may well be independent of the investment that created the tie (Bygrave 1987, 1988). Finally, multiple ties between two organizations may result from multiple joint investments in different start-ups, which will allow for an increased amount and quality of information flowing between them (Bygrave 1988).

The number and strength of ties that a VC has with its peers is thus an essential source of information it may use to leverage its portfolio investments. This is captured by a specific structural network attribute, 
namely, the number of connections the VC has (also accounting for the fact that a connection with the same partner may occur repeatedly). Ceteris paribus, the more information the $\mathrm{VC}$ has available to use, filter, or recombine, the higher the likelihood that it can extract value from this information (Uzzi 1997).

In our setting, the more connections an investor holds, the higher the likelihood that this investor will become aware of new high-quality investment prospects, as well as of opportunities that can be used to leverage (also more widely known) investment prospects if they were to become part of its portfolio. As argued previously, both factors should positively impact a VC's anticipated returns from the investment object being considering, relative to investors with fewer network connections. This will increase the focal VC's willingness-to-invest-that is, both the likelihood of investment as well as the amount of funds invested-into this start-up, which will result in the start-up ultimately receiving higher investment funds. However, it might be naïve to assume that anyone could establish and maintain an unlimited number of connections to other parties. On the contrary, keeping a network tie to another party alive and healthy requires actors to bear significant cost and effort, while the additional information a new connection can add will decrease (Uzzi 1997). Considering that management attention and information processing capability is limited (Ocasio 1997), we expect that, after a certain threshold, the marginal value that an additional network connection can add for the firm will begin to decrease, and that it might even turn negative (Uzzi 1997). Consequently, we can formulate two hypotheses that:

Hla [valued degree: linear] The number of connections investors have in the syndication network prior to their investment in the start-up will have a positive effect on the funds raised by the start-up in an investment round.

H1b [valued degree: curvilinear] With an increasing number of connections investors have in the syndication network prior to their investment in the start-up, the positive effect of an additional connection on the funds raised by the start-up in an investment round will decrease.

In addition to the sheer volume of incoming information, the quality and uniqueness of incoming information should fundamentally impact a VC's ability to engage in information arbitrage. Burt's work (1982, 1992, 2005) shows how a structurally advantageous network position may give actors in a network privileged access to such information. In the literature on social capital, there is ongoing debate of whether such advantages are derived from open of closed network structures (Arenius and De Clercq 2005; Burt 2005; Soda et al. 2004).

Existing studies at the interface of networks and social capital have conceptualized the network structure associated with social capital in two different ways. Burt (2005) favors the view that social capital is derived from open network structures, arguing that firms or individuals that span structural holes in networks can acquire unique rents through information arbitrage. The spanning of structural holes happens when an individual or firm is the sole link between two otherwise disconnected individuals or groups. The argument is that, in such a case, all information that has to travel from one group to the other must travel through the person or firm in the middle, the so-called broker (Burt 2005). Since the broker is the only person who has access to both pools of disconnected knowledge (or: resource), he or she is in a position to act strategically to derive personal benefits through information arbitrage. For example, the broker may selectively pass on or, alternatively, hold back information from one group according to the broker's best interest, or he/she may charge a fee for either action. Alternatively, the broker may bring together information from the disconnected groups and combine them into a superior, more valuable configuration. The latter is, for example, crucial in innovation problems, which are often successfully solved by individuals at the interface between different fields (Jeppesen and Lakhani 2010). Conversely, Coleman (1990) argues that firms or individuals gain most from being embedded in closed network structures. Closed structures act as vehicles of trust, promoting the exchange of sensitive information and the establishment of common norms and routines among members of dense parts of a network (Uzzi 1997).

In empirical research, both brokerage and closure have been demonstrated to lead to positive outcomes in a wide variety of settings (Ahuja 2000; Fleming et al. 2007; Rodan and Galunic 2004). Although closure and brokerage are direct conceptual 
opposites - and hence are often measured by a single indicator - there are increasing attempts to unite both approaches, examining the conditions under which one might be more relevant than the other. Most notably, it is argued that when fast access to information is important, brokerage may be more advantageous than closure; as a consequence, brokerage is particularly relevant in fast-paced, competitive environments (Burt 2009). For example, Rowley et al. (2005) show that the advantages of brokerage are contingent upon the level of turbulence in an industry. Likewise, Zaheer and Bell (2005) suggest that in a context in which the speed of new product development is high, a network rich in structural holes may be more beneficial than a network with high closure.

Speed of access to information, such as in terms of promising investment opportunities, is of utmost importance in the context of VC investments (Bygrave 1987, 1988). Therefore, we argue that VCs derive social capital from structural holes in the network rather than from closure. More precisely, we argue that a VC that is able to span structural holes should readily have access to unique and valuable information related to both the pre- and post-investment phase. Furthermore, the more structural holes a VC spans (i.e., the fewer connections that exist between the members of a VC's network), the higher the likelihood that the focal VC is the only one to know about prospective investments and/or future opportunities to leverage. As a consequence, this VC should, following our earlier argumentation, arrive at a higher willingness to invest into the focal venture, which will ultimately increase the amount of funds this venture will receive in a funding round. Thus, we specify as our second hypothesis:

H2 [structural holes] The more an investor is spanning structural holes in the syndication network prior to their investment in the start-up, the higher the funds raised by the start-up in an investment round.

\subsection{Relational aspects and investment sum}

Relational attributes refer to the characteristics that network partners have, and how these compare with each other and to the focal organization. They thus capture the fact that it is important and relevant to the organization with whom it is connected, implying that diversity or similarity of connections will affect social capital (Granovetter 1985; Reagans and McEvily 2003). In this study, we focus on diversity among a VC's syndication partners in terms of the structure of their portfolio of past investments to capture relational attributes of social capital.

Interestingly, past literature is split on whether it is similarity or diversity of partners in the social network that might be a more potent source of information arbitrage. Diversity will give a VC access to more exclusive and varied information (Almeida and Kogut 1997; Granovetter 1985), going beyond the advantages associated with the mere spanning of structural holes (Fleming and Waguespack 2007). Generally, the social networks and social capital literature would argue that, with increasing diversity in the relational attributes of an actor's network, the higher the likelihood that this actor has access to rich, unique, and varying information (Reagans and McEvily 2003). Furthermore, information from outside the domain of the focal actor, provided that it fits the actor's needs, is likely to have a higher impact on performance-related outcomes. For example, as Poetz and Schreier (2009) show, problem solutions that are based on analogies from more cognitively distant fields are likely to be more innovative than those based on local knowledge. In our case, access to more diverse information should thus provide VCs with access to more unique opportunities, in particular regarding their identification in the post-investment phase. For example, being linked to investors that have prior investments in a diverse range of technological fields will give a $\mathrm{VC}$ a higher chance of receiving a certain unique piece of information, for example about an upcoming technology, than VCs without this type of relation. That is, being linked to investors that have diverse investment portfolio structures might give the focal VC unique information in the form of new markets for start-ups it has invested in.

On the other hand, much of the existing venture capital literature and its wider theoretical foundations strongly argue in favor of specialization. At the core of the argument is the idea that being embedded in a network of similarly specialized VCs will increase the focal VC's ability to extract valuable information from the network and efficiently and effectively 
process it (Bygrave 1987). In particular, in fast moving areas, specialization will be the only way to keep up with technological progress and guarantee the ability to process newly incoming information relating both to the pre- and post-investment phase (Bygrave 1987; De Clercq and Dimov 2004). Repeated engagement with partners that invest in similar industries or sectors should lead to VCs being able to build specific routines and capabilities for doing so. Similarly, a smaller cognitive distance between the VC and its network partners will increase the VC's effectiveness in processing information sent out by the partners (Gulati 1995; Nooteboom 2000; Uzzi 1997). This will make it easier for the focal VC to use this information to learn about new investment prospects and opportunities to leverage them, which could for example reside in collaborating with a similar firm in the portfolio of one of the partners. Thus, specialization regarding the structure of their investment portfolios as compared to each other and relative to the $\mathrm{VC}$ firm, might enable the $\mathrm{VC}$ to extract more reliable and higher-quality information from its social network. The effects of this are shown by Dimov and De Clercq (2006), who find that VCs following a specialization strategy actually see a lower default rate in their portfolio.

Summarizing, extant theory on social networks and venture capital makes competing claims concerning the effects of similarity/diversity on VCs' ability to benefit from information that is flowing through their social network. Thus, we can derive competing hypotheses for the effect of similarity/ diversity in terms of the structure of the portfolios of past investment partners on the investor's ability to draw valuable information from the network. That is, we arrive at two competing logics for how these two relational attributes of the network may improve the firms' ability to profit from information in its social network. Identical to the arguments we presented for the effect of network structure on investment sum, we can say that, whichever explanation holds true, VCs having superior information due to the relational aspects of their social network will again be in a preferential position when making an investment decision. They will have better knowledge about both upcoming investment prospects and how to potentially leverage them, using suitable information extracted from the social network. Similar to H1 and $\mathrm{H} 2$, and taking into account that two competing logics for the effects of relational network attributes exist, we thus state:

H3a [past investments: diversity] The more diverse investors' networks in terms of the fields of investment of its past syndication partners prior to the investment in the start-up, the higher the funds raised by the start-up in an investment round.

H3b [past investments: similarity] The more similar investors' networks are in terms of the fields of investment of its past syndication partners prior to the investment in the start-up, the higher the funds raised by the start-up in an investment round.

Finally, we also note that our hypotheses, in fact, might not be competing, but indicative of a non-linear effect. For example, one might imagine that both very similar and very diverse syndication networks might help VCs in generating social capital. Yet again, we are not aware of corresponding theory that would allow us to make a clear prediction. Rather, we will control for potential non-linear effects in an exploratory fashion when analyzing our data.

\section{Data and method}

\subsection{The CrunchBase data set}

As a data source, we make use of a novel dataset obtained from the web site CrunchBase (Block and Sandner 2009). CrunchBase can be best viewed as a "repository" of start-up companies, individuals, and investors having a focus on U.S. high-tech sectors (in particular IT and Internet). CrunchBase describes itself as a "free database of technology companies, people, and investors that anyone can edit." Also complying with the characteristics of a repository, CrunchBase offers-at least for the last yearsalmost complete coverage of start-ups and investors in the Internet sector, including the relationships between them. Therefore, we can derive longitudinal, valued, network-based structural and relational measures, while other work in this area often rests on cross-sectional, survey-based, positional measures (Hoang and Antoncic 2003). CrunchBase is operated by TechCrunch located in the Silicon Valley (California), one of the most popular Internet blogs and information sources on technological innovations and 
market developments related to high-tech sectors in general and the Internet in particular. CrunchBase itself serves as a data provider for TechCrunch, as the latter frequently embodies standardized start-up or investor profiles from CrunchBase in the published articles.

Our analysis is based on data obtained from CrunchBase in early 2010. As of February 15, 2010, CrunchBase included information on 34,302 firms, 3,843 financial organizations, and 11,375 funding rounds. The companies covered by CrunchBase span a wide spectrum. On the one hand, large companies like Google or eBay are included in the dataset. On the other hand, small start-up companies that might have been founded recently or do not rely on thirdparty investments are included as well. Thus, as the database covers privately held companies with very few employees as well as multi-billion dollar businesses, the spectrum of companies included is wider compared to other company databases. As we seek to analyze the social capital of VCs, our first step is to remove those 7,926 companies that do not receive any funding. Because of our focus on U.S. high-tech sectors (in particular, the IT and Internet sector-a focus that also holds true for both CrunchBase and TechCrunch), we then exclude those companies not related to the IT and Internet sectors. This results in a sample of 5,649 start-up companies in the areas of advertising, e-commerce, enterprise software and services, games and video, hardware, mobile, network hosting, search, security, software, and web. Second, we drop those start-up companies that are not based in the USA (1,381 observations) or whose domicile is unknown (600 start-ups), arriving at a reduced sample of 3,668 start-up companies. Third, we only consider those financial organizations that have invested in the start-ups above and which have significant activities in the USA, which reduces our sample to 1,688 of the total 3,843 financial organizations. We compute our network metrics and conduct our regression analysis on these reduced samples. This implies that both our analysis and the conclusion will also reflect the structure of our sample and might thus potentially be limited to a North American Internet and IT setting. Consequently, as a robustness check, we also conduct an analysis identical to the one above, but in which we do not drop the observations originating from other industries, affecting both the social network of VCs resulting from the syndication data as well as the other variables entering the regression. The results remain largely identical, with all variables of interest keeping their sign and only minor changes in coefficient sizes and levels of significance. Finally, to exclude effects such as learning, sustained or disrupted syndication networks, or varying investor motivations between subsequent investment rounds in the same firm, we only consider the first funding round into a new venture for our analysis. ${ }^{2}$ Our final sample thus contains 3,173 unique VC investments in 1,649 different first funding rounds.

\subsection{Social network analysis-the network}

The CrunchBase dataset is a formidable dataset to employ for social network analysis as it covers almost complete relationships between start-ups and VCs. This is contrasted by other research relying on survey data as the latter leads to methodological difficulties since networks can only partly be observed. The relationships between start-ups and VCs-materializing through investments (i.e., funding rounds)—is thus the point of departure for calculating the network metrics on the VC syndication network. This syndication network is a one-mode representation of a twomode network; a network of investors (one-mode) is created on the basis of investments by investors in startups (two-mode). The value of links in the onemode network among investors-i.e., the syndication network-is given by the number of times they have jointly invested in the same startup firm. Using a 5-year moving window procedure, the investment volume of a funding round in which a VC participates in year $t$ is regressed on metrics of the VC's position in the syndication network covering the 5 years preceding that investment. The syndication network that was generated in this way is shown in Fig. 1 at three different points in time. The network grows substantially over the complete observation period, from 110 unique investors in 1998-2002 up to 1,050 unique investors in 2005-2009.

\footnotetext{
$\overline{2}$ We are indebted to an anonymous reviewer for bringing this issue to our attention.
} 


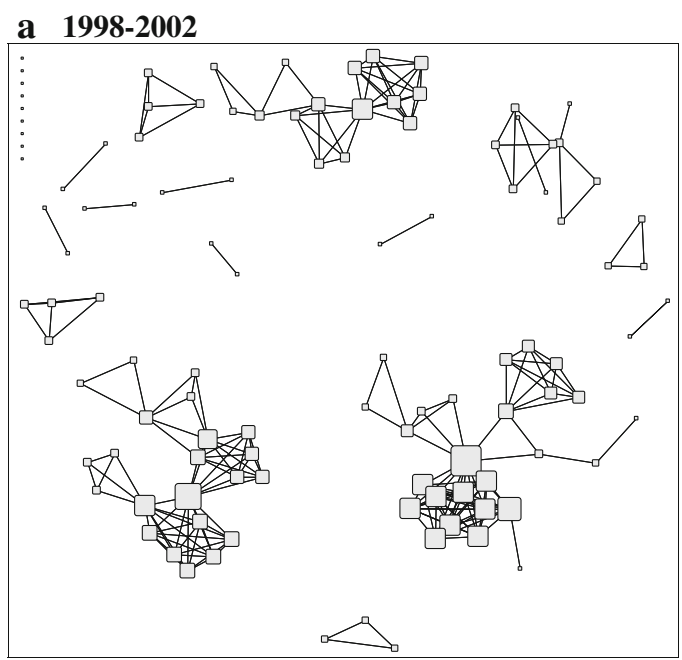

b 2001-2005
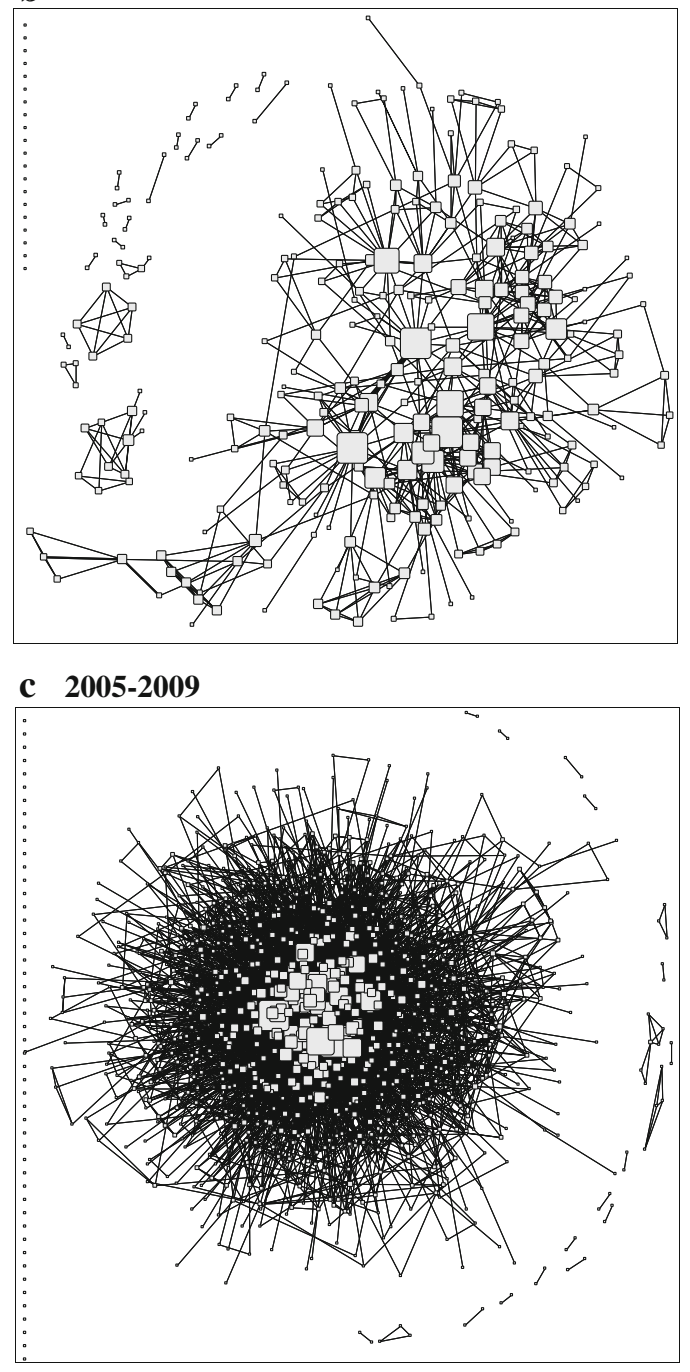

Fig. 1 Venture capitalist (VC) syndication networks over time. Nodes represent VCs, lines represent joint investments in a start-up firm through syndication. The size of the nodes indicates their degree centrality in the network

\subsection{Dependent variable}

Our dependent variable is the amount of funds raised by the focal start-up in its first funding round (variable funds raised). The measure reflects realized - rather than intended-investments (Dimov and De Clercq 2006). In addition, this variable may also be regarded as a proxy for the value of the firm at the time when the investors jointly conducting a funding round equip the start-up with VC money. Since the variable is highly skewed in nature, we apply the natural logarithm of this variable in our regression model.

\subsection{Independent variables-social network measures}

\subsubsection{Valued degree}

To test the first hypothesis, we measure the number of connections VCs have in the syndication network. In network terminology, we measure the valued degree (Wasserman and Faust 1994). This is a centrality measure that indicates the number of direct coinvestment relationships, where (vs. the unvalued degree) multiple co-investment relations with the same partner are also counted as such. To cater to potential multicollinearity issues, we divide this number by the number of investments a VC has made in the same 5-year moving window.

\subsubsection{Network constraint}

In order to measure the effect of structural holes on investment sum, we use Burt's constraint measure (1992, p. 55). Network constraint is an index that measures the extent to which a person's contacts are redundant. More precisely, the lack of structural holes in a VC's network of direct relations-also referred to as network redundancy-is measured by the extent to which relations are directly or indirectly concentrated in a single contact. For each node in a focal VC's network, we calculate which proportion of the 
focal VC's direct connections directly or indirectly have a network path through that node. The constraint measure is the sum of squared proportions for all nodes in the VC's network of direct syndication links. The richer a network of a VC's network of direct syndication partners is in structural holes, the lower constraint, and the more opportunities for information arbitrage should exist.

\subsubsection{Network specialization index}

Diversity in a VC's network can also result from the sub-sectors within the IT sector in which its syndication partners have invested. The network specialization index calculates the specialization/diversity of a focal VC's investment portfolio relative to those VCs to which it is connected. On the basis of their investment history over the 5 years preceding the focal investment, we calculated the extent to which a VC's past syndication partners have invested in a similar versus diverse range of subsectors. That is, for each investor we defined a vector specifying the shares of its investments over 11 subfields. Taking the cross-product of vectors for each pair of investors (Bonacich 1972) results in a matrix with values between 0 and 1 that specifies the relative extent to which two investors focus on the same subsectors for all combinations of investors. To obtain a measure for each investor that relates only to those other investors to which it is connected, we then calculated a weighted average of this pairwise specialization index, where the weight is the value of the connection (the number of times two investors co-invested in a start-up in a moving 5-year period; 0 if unconnected). In the final index a value of 1 represents the situation where a VC's syndication partners exclusively invested in the same subfields as the focal VC (a specialized network) and 0 a situation in which a VC's syndication partners invested in entirely different subfields as the focal VC (a diverse network).

\subsection{Control variables}

To not confound the effects of the VC's social network with other effects, we include a number of control variables. Based on a careful review of extant literature (Block and Sandner 2009; De Clercq and Dimov 2004; Dimov and Shepherd 2005; Dimov et al. 2007), we include variables related to the characteristics of the start-ups, the investors and the respective funding rounds.

\subsubsection{Start-up characteristics}

To distinguish between early-stage and later-stage start-ups, we include the age of the start-up (in days). Since this variable is highly skewed, we take its natural logarithm. To distinguish between start-ups belonging to different subsectors within the Internet and IT industry, we include the more fine-grained indicator variables: consumer web, electronic commerce, enterprise, advertising, games/video/entertainment, hardware, mobile/wireless, software, network hosting, search, and security. The categorization is based on the categories provided by CrunchBase. Moreover, we include the start-up's number of registered patents and trademarks at the time of investment as controls for the level of innovation orientation and appropriability efforts (Jell et al. 2011; Mendonça et al. 2004; Sandner and Block 2011; Wagner and Cockburn 2010). As both measures are highly skewed, we take their natural logarithms.

\subsubsection{Investor characteristics}

As a proxy for the experience of the VC investor, we include 11 variables indicating the number of prior investments in the above noted industries (to control for industry and general investment experience). In addition, we inserted dummy variables indicating whether the investor is a business angel, a (financially oriented) $\mathrm{VC}$, or a strategic investor (industrial firm or corporate $\mathrm{VC}$ ).

\subsubsection{Funding round characteristics}

To control for funding round characteristics, we calculate the number of participants in the funding round and insert this variable in linear and squared terms. To account for business cycle effects in the provision of VC (Block and Sandner 2009; Block et al. 2011), we include several year dummies. Finally, we insert 36 U.S. state dummies to control for potential regional disparities, such as in the provision of venture capital (Sorenson and Stuart 2001). 


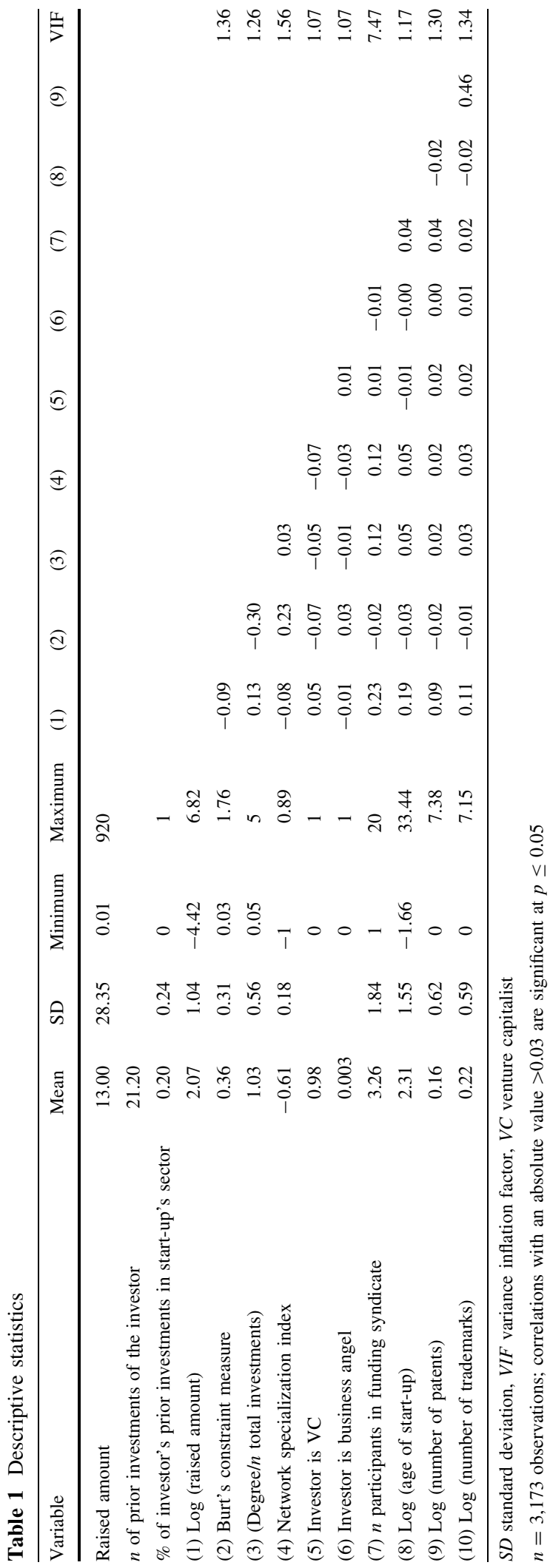

\section{Results}

\subsection{Descriptive statistics}

Table 1 presents the descriptive statistics and correlations of the variables in our regression models. Not surprisingly, the social network measures are correlated with each other. For example, the higher the investor's degree, the more likely this financial organization is able to span structural holes. Yet, given the large number of observations in our dataset $(n=3,173)$, we regard the potential issue of multicollinearity to be only of minor concern. The variance inflation factors (VIFs) belonging to our independent variables are relatively low. Some descriptive statistics are noteworthy: about $98 \%$ of investors are VCs; only a small portion of investors are strategic investors, such as industrial firms $(2 \%)$ or business angels $(0.3 \%)$. The mean syndicate size is 3.3 , and the mean number of total investments of each investor is 21 . About $20 \%$ of all prior investments of the investors were in the start-up's sector. This may seem low but can be explained by the finegrained categories which we use. The mean investment sum per funding round is US\$ 13 million. However, this number is highly skewed. The median investment sum is "only" 9 million. To account for this high degree of skewness in the regressions, we use the natural logarithm of the raised amount.

\subsection{Regression analysis}

As explained above, our unit of analysis is the individual VC participating in the start-up's first funding round. We argue that the amount raised in the first funding round depends on VCs' social capital as derived from the social network created through past syndication. Table 2 shows different regression specifications, with the amount of funds raised in the focal funding round as the dependent variable. Model I contains the control variables and all but one of our variables of interest. Namely, in Model II, we add the squared term of valued degree, and we can interpret both the change in model fit as well as the significance level of this coefficient to understand the effect of this variable. Model II is thus our preferred specification. Finally, in Model III, we explore potential non-linear effects of the relational network attributes. To do so, we replace the network 
Table 2 Linear regression on $\log$ (raised amount)

\begin{tabular}{|c|c|c|c|}
\hline Independent variables & $\begin{array}{l}\text { Model I } \\
\text { Coeff (SE) }\end{array}$ & $\begin{array}{l}\text { Model II } \\
\text { Coeff (SE) }\end{array}$ & $\begin{array}{l}\text { Model III } \\
\text { Coeff (SE) }\end{array}$ \\
\hline \multicolumn{4}{|l|}{ Investor's social network position } \\
\hline Burt's constraint measure & $-0.29(0.07)^{* * *}$ & $-0.25(0.07)^{* * *}$ & $-0.32(0.07) * * *$ \\
\hline Degree/ $n$ total investments & $0.16(0.04)^{* * *}$ & $0.28(0.10)^{* * *}$ & $0.15(0.04) * * *$ \\
\hline$\left(\right.$ Degree/ $n$ total investments) ${ }^{2}$ & & $-0.042(0.031)$ & \\
\hline Network specialization index & $-0.58(0.15)^{* * *}$ & $-0.59(0.15)^{* * *}$ & \\
\hline Absolute value of network specialization index & & & $0.45(0.16)^{* * *}$ \\
\hline \multicolumn{4}{|l|}{ Other investor characteristics } \\
\hline Investor is $\mathrm{VC}$ & $0.22(0.29)$ & $-0.22(0.29)$ & $-0.24(0.30)$ \\
\hline Investor is business angel & $0.11(0.19)$ & $0.11(0.19)$ & $0.10(0.19)$ \\
\hline Investor is strategic investor (reference cat.) & & & \\
\hline$n$ investments in the respective industry sectors & 11 cat. $(p<0.01)$ & 11 cat. $(p<0.01)$ & 11 cat. $(p<0.01)$ \\
\hline \multicolumn{4}{|l|}{ Funding round characteristics } \\
\hline$n$ participants in funding syndicate & $0.33(0.04) * * *$ & $0.33(0.04)^{* * *}$ & $0.33(0.04)^{* * *}$ \\
\hline ( $n$ participants in funding syndicate $)^{2}$ & $-0.025(0.005)^{* * *}$ & $-0.025(0.005)^{* * *}$ & $-0.025(0.005)^{* * *}$ \\
\hline Log (age of start-up) ${ }^{\mathrm{a}}$ & $0.13(0.03)^{* * *}$ & $0.13(0.03)^{* * *}$ & $0.13(0.03)^{* * *}$ \\
\hline Log (number of patents) & $0.03(0.04)$ & $0.03(0.04)$ & $0.03(0.04)$ \\
\hline Log (number of trademarks) & $0.15(0.04)^{* * *}$ & $0.15(0.04)^{* * *}$ & $0.14(0.04) * * *$ \\
\hline Sector dummies (reference cat.: security) & 10 cat. $(p<0.01)$ & 10 cat. $(p<0.01)$ & 10 cat. $(p<0.01)$ \\
\hline Year dummies (reference cat.: year 2003) & 9 cat. $(p<0.01)$ & 9 cat. $(p<0.01)$ & 9 cat. $(p<0.01)$ \\
\hline State dummies (reference cat: California) & 36 cat. $(p<0.01)$ & 36 cat. $(p<0.01)$ & 36 cat. $(p<0.01)$ \\
\hline Constant & $1.53(0.42)^{* * *}$ & $1.45(0.44)^{* * *}$ & $1.65(0.42) * * *$ \\
\hline$n$ investment observations (funding rounds) & $3,173(1,649)$ & $3,173(1,649)$ & $3,173(1,649)$ \\
\hline$F$ test & $p<0.01$ & $p<0.01$ & $p<0.01$ \\
\hline$R^{2}$ & 0.31 & 0.31 & 0.31 \\
\hline
\end{tabular}

Two-sided tests: $* p \leq 0.10, * * p \leq 0.05, * * * p \leq 0.01$

Sample: only first funding rounds

Coeff Coefficients, $S E$ robust and clustered standard error, cat. category

a Observations with missing values are proxied by the sample mean. To control for this, we included also a dummy variable which indicates whether the firm age was missing or not. The variable shows a significant effect (e.g., $\beta=0.37 * * *$ in Model I)

specialization index (originally ranging from -1 to 1 ) with its absolute values, so that higher values represent high levels of either similarity or diversity, and lower values are indicative of the use of hybrid forms in between.

Looking at Model II, most of our hypotheses relating to the VCs' social capital are supported. We first look at our hypotheses on the effect of the structural attributes of VCs' syndication networks on funds raised in an investment round. In support of H1a, we find that the higher the investor's degree of connection to other investors, the higher the start-up's amount of funds raised in the respective funding round $(\beta=0.28, p<0.01)$. In contrast, we only find marginal support for H1b: the squared term of the investor's degree of connection to other investors points in the right direction $(\beta=-0.04)$, but it only becomes weakly significant when a one-sided test is applied ( $p=0.09$; one-sided test). ${ }^{3}$ Nonetheless, when controlling whether the coefficient values of degree and its squared term are truly indicative of a curvilinear effect, we find that the variable degree/n total investments has an absolute positive effect on investment sum up to a value of 3.33 , after which it turns negative (about $99 \%$ of our sample falls into

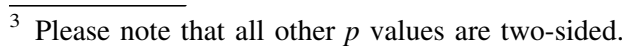


this range). Finally, Burt's constraint measure (H2) shows the hypothesized negative effect on the amount of funds raised $(\beta=-0.25, p<0.01)$. That is, the more the $\mathrm{VC}$ investors are spanning structural holes in the syndication network prior to the investment in the start-up, the larger the amount of funds raised in the particular funding round, and $\mathrm{H} 2$ is confirmed.

Our results further support our arguments on the role of relational aspects of VCs' syndication networks in general and of network partners' investment portfolios specifically (H3). The more diverse the syndication network of the VC in terms of the sectors in which the investor's prior syndication partners invested (relative to the VC), the higher the amount of funds raised by the start-up in the first funding round (H3a, $\beta=-0.59, p<0.01)$. However, when we control for the possibility of a non-linear effect, we find indications that both specialization and diversity may in fact matter. Specifically, when we transform the network specialization index to a format in which 0 indicates a perfectly hybrid strategy between similarity and diversity, and 1 may stand both for a perfectly similar and a perfectly diverse network (see Model III), we see that the coefficient for network diversity/specialization in terms of IT sectors carries a positive sign and remains significant (Model III: $\beta=0.45, p<0.01$ ). This indeed indicates that both similar and diverse networks may have positive effects on the investment made by the VC when compared to hybrid approaches.

\section{Discussion and implications}

\subsection{Discussion of results}

In this paper, we looked at the effects of VCs' social capital, originating from the relational and structural attributes of VC syndication networks, on investments made into start-up firms. Regarding the structural dimension of social capital, we find that brokerage has a significant effect which is significant in all specifications. Also, the variable capturing the number of connections has a positive effect on investments made, with some indications of curvilinearity. The relational elements of social capital also shows an effect. We found that diversity in terms of investment portfolio in a VC's syndication network is positively associated to the investment sum. Furthermore, exploratory analysis showed that both high levels of specialization and diversity of a VC's syndication network have positive effects on investment sum. In the following, we analyze the implications of these findings for theory and practice.

\subsection{Implications for theory}

With this study, we make three contributions to the literature on entrepreneurship and venture capital. First, we indicate how the structure of past syndication networks affects investment into start-ups by facilitating knowledge flows between the involved investors (Bygrave 1987, 1988). We highlight the effects of degree and brokerage, which represent, respectively, the sheer volume of incoming information available to an investor and the uniqueness of this information, resulting in opportunities for information arbitrage. First, we show that the sheer amount of information that VCs have at their disposal will increase the amount of money they put into startups. In doing so, we show that structural embeddedness (Uzzi 1997) in the social network of investors has a clear effect on the investment decisions that VCs make. In addition, we show that brokerage (Burt 2005), as in many other fields, matters for venture capital. Specifically, the spanning of structuring holes allows VCs to achieve abnormal returns and lower risk through information arbitrage (Burt 2005), thus positively affecting their willingness to spend money on a start-up.

Second, we add to the literature by shedding light on the role and importance of relational network attributes. In particular, we offer a new perspective on the debate about the relative advantageousness of investors having either similar (Bygrave 1987; De Clercq and Dimov 2004; Dimov and De Clercq 2006) or diverse (Fleming and Waguespack 2007; Granovetter 1985; Reagans and McEvily 2003) syndication networks. Importantly, we show that, in terms of the relative composition of network partners' investment portfolios, diverse networks affect investment sum more strongly than similar ones. However, on closer inspection, we see that both similarity and diversity have positive effects on the information available to a $\mathrm{VC}$ and the investments they are willing to make. Thus, our findings suggest that VCs may be successful by strategically building networks alike to both 
focused boutiques as well as broad generalists. Both archetypes of networking strategy and design seem to facilitate improved access to information as compared to hybrids. Boutiques should have higher chances at processing valuable information flowing through their network, whereas generalist may have a chance of receiving, on average, higher value information. In turn, following our theoretical argumentation, both boutiques and generalists may show higher willingness to invest in a focal start-up. These start-ups, as a consequence, need not have a preference for any of the two archetypes as long as the VC either has a clear specialization or diversity strategy with regards to their approach to the selection of syndication partners.

Taken together, our main contribution lies in extending the current perspective on venture capital and its role in entrepreneurship by applying a comprehensive social capital perspective. Overall, we clearly show that the social capital of VCs, derived from the structural and relational attributes of the syndication networks they are embedded in, matters with respect to the investment decisions they take and, consequently, the amount of funding that start-ups may receive. In doing so, our findings further allow us to add to an ongoing debate which suggests that VCs' social capital might actually need to be "bought" or "paid for" by the new venture, as reflected in entrepreneurships' willingness to accept lower offers of financial capital from well-networked VCs (Hsu 2004). Whereas our findings on the nature of the relationship between financial and social capital are not fully conclusive (see below), they nevertheless allow us to speculate that this relationship might be complementary, rather than substitutive. Indeed, we find that start-ups that are invested in by high social-capital VCs receive higher levels of funding that those new ventures supported by low social-capital VCs, and we identify the elements of social capital that drive these investments. In so doing, we show that the role and nature of VCs' social capital might be much more complex than previously stated in the respective literatures. This claim is further supported by some of our more specific results which, for example, illustrate that both similarity and diversity in the social network may lead to higher investments, whereas hybrid strategies do not (Uzzi 1997). However, we need to emphasize that further research into all elements of social capital brought forward in this paper is needed to truly understand the effect of VCs' social capital on the investment decisions they make in practice. In particular, we believe that our work raises a call for more qualitative work to investigate and scrutinize this issue, as our understanding of the processes inside venture capital organizations, including their management and use of social capital as well as the effect of the latter on the ventures in their investment portfolio, is currently limited at best. In addition, because of data limitations, we cannot clearly say whether start-ups received higher investment sums from high-social capital VCs because those had a higher willingness-to-pay for the same share of ownership in the new venture or because they bought a larger share of ownership over the new venture. Accordingly, we call for future research to extend our work on this important question.

\subsection{Implications for practice}

Our results have practical relevance for both VCs and entrepreneurs. For VCs, they further indicate the importance of social capital, which they will need to build and maintain through suitable strategies. Specifically, we point out that both a strong diversification as well strong specialization strategies seem to have merits, whereas hybrid forms could be of lower value. Regarding the start-up, we find that they do not have to be shy about approaching high-social capital VCs. Indeed, if there is a chance their social capital is beneficial to a specific deal, there is no reason why this should result in the start-up receiving a discount on their inherent valuation. In fact, the opposite may hold.

\subsection{Suggestions for future research}

In addition to those already stated earlier, this study opens up several avenues for future research on the role of social capital for investors in general and for their funding of new ventures and their eventual success in particular. First, regarding investor strategies aimed at building social capital, we did not find the expected curvilinear effect on investment sum that we had expected, and we encourage future research to investigate why. Similarly, while our results allow us to point out that both similarity and diversity in the social networks of VCs should have 
positive effects on them extracting valuable information from the network, we cannot draw any conclusions on the circumstances under which one of the two strategies would be preferable, and thus leave this question open for future research. Finally, our paper raises the question of how social capital in general, and specific attributes of it, may affect new ventures beyond the funding decision. In particular, we encourage future research to take a closer look at the impact of VCs' social capital on new venture survival, growth, and, ultimately, success.

\subsection{Limitations and conclusion}

Some limitations of our study need to be mentioned. First, we do not observe exact ownership percentages by VCs in a funding round. However, since we control both for the size of the syndicate as well as for many other characteristics, we do not expect this effect to have a large impact on our results. Similarly, our data are biased towards North American IT and Internet firms. Yet, as stated earlier, a robustness check that included all of the reliable investment information available to us (worldwide and across many different industries) provided almost identical results, with all results reported qualitatively unchanged. Nevertheless, future research that can link the CrunchBase dataset to other sources that may cater to its disadvantages (e.g., VentureExpert) will help to ensure the validity of our findings. Second, we do not observe founder characteristics, such as industry or entrepreneurship experience. Zhang (2011) shows that serial entrepreneurs have an advantage in venture capital acquisition.

Limitations aside, our study has shed new light on the role of VCs' social capital for the entrepreneurship and venture capital literatures, showing that its effects are likely to be more complex than previously hypothesized. While answering some questions on this issue, we have simultaneously created many new ones, which we hope will encourage further research on this topic. Given this background, we believe that our study can provide a valuable building block to help improve our still limited understanding of the role of VCs' social capital and its effects on the startup firms they invest in.

Acknowledgments Oliver Alexy and Anne Ter Wal are grateful for financial support from the Engineering and
Physical Sciences Research Council's IMRC at Imperial College London. The authors gratefully acknowledge feedback from Martin Kilduff and Isabell M. Welpe, as well as participants at the Babson College Entrepreneurship Research Conference 2010, the G-Forum 2010, the UK-IRC early career researcher workshop 2010, and the IECER Conference 2011. The authors further thank two anonymous reviewers and the editor of the journal for constructive comments. All authors contributed equally to the manuscript.

Open Access This article is distributed under the terms of the Creative Commons Attribution Noncommercial License which permits any noncommercial use, distribution, and reproduction in any medium, provided the original author(s) and source are credited.

\section{References}

Ahuja, G. (2000). Collaboration networks, structural holes, and innovation: A longitudinal study. Administrative Science Quarterly, 45(3), 425-455.

Aldrich, H. E., \& Zimmer, C. (1986). Entrepreneurship through social networks. In D. L. Sexton \& R. W. Smilor (Eds.), The art and science of entrepreneurship (pp. 3-23). New York: Ballinger.

Almeida, P., \& Kogut, P. (1997). The exploration of technological diversity and the geographic localization of innovation. Small Business Economics, 9(1), 21-31.

Arenius, P., \& De Clerq, D. (2005). A network-based approach on opportunity recognition. Small Business Economics, 24(3), 249-265.

Audretsch, D., \& Thurik, R. (2001). What is new about the new economy: Sources of growth in the managed and entrepreneurial economies. Industrial and Corporate Change, 10(1), 267-315.

Block, J., de Vries, G., \& Sandner, P. (2011). Venture capital and the financial crisis: An empirical study across industries and countries. In D. Cumming (Ed.), The handbook of venture capital. London: Oxford University Press.

Block, J., \& Sandner, P. (2009). What is the effect of the financial crisis on venture capital financing? Empirical evidence from US Internet start-ups. Venture Capital, 11(4), 295-309.

Bonacich, P. (1972). Techniques for analyzing overlapping memberships. In H. L. Costner (Ed.), Sociological methodology. San Francisco: Jossey-Bass.

Brander, J. A., Amit, R., \& Antweiler, W. (2002). Venturecapital syndication: Improved venture selection vs. the value-added hypothesis. Journal of Economics and Management Strategy, 11(3), 422-451.

Brüderl, J., \& Preisendörfer, P. (1998). Network support and the success of newly founded business. Small Business Economics, 10(3), 213-225.

Burt, R. S. (1982). Toward a structural theory of action: Network models of social structure, perception, and action. New York: Academic Press.

Burt, R. S. (1992). Structural holes: The social structure of competition. Boston: Harvard University Press. 
Burt, R. S. (2005). Brokerage and closure: An introduction to social capital. New York: Oxford University Press.

Burt, R. S. (2009). Neighbor networks: Competitive advantage local and personal. New York: Oxford University Press.

Burton, M. D., Sørensen, J. B., \& Beckman, C. M. (2002). Coming from good stock: Career histories and new venture formation. In M. Lounsbury \& M. J. Ventresca (Eds.), Research in the sociology of organizations (Vol. 19, pp. 229-262). Greenwich, CT: JAI Press.

Bygrave, W. D. (1987). Syndicated investments by venture capital firms: A networking perspective. Journal of Business Venturing, 2(2), 139-154.

Bygrave, W. D. (1988). The structure of the investment networks of venture capital firms. Journal of Business Venturing, 3(2), 137-157.

Coleman, J. S. (1988). Social capital in the creation of human capital. American Journal of Sociology, 94(s1), S95.

Coleman, J. S. (1990). Foundations of social theory. Cambridge, MA: Harvard University Press.

De Clercq, D., \& Dimov, D. P. (2004). Explaining venture capital firms' syndication behaviour: A longitudinal study. Venture Capital, 6(4), 243-256.

De Clercq, D., Fried, V. H., Lehtonen, O., \& Sapienza, H. J. (2006). An entrepreneur's guide to the venture capital galaxy. Academy of Management Perspectives, 20(3), 90-112.

Dimov, D., \& De Clercq, D. (2006). Venture capital investment strategy and portfolio failure rate: A longitudinal study. Entrepreneurship: Theory and Practice, 30(2), 207-223.

Dimov, D. P., \& Shepherd, D. A. (2005). Human capital theory and venture capital firms: Exploring "home runs" and "strike outs". Journal of Business Venturing, 20(1), 1-21.

Dimov, D., Shepherd, D. A., \& Sutcliffe, K. M. (2007). Requisite expertise, firm reputation, and status in venture capital investment allocation decisions. Journal of Business Venturing, 22(4), 481-502.

Fitza, M., Matusik, S. F., \& Mosakowski, E. (2009). Do VCs matter? The importance of owners on performance variance in start-up firms. Strategic Management Journal, 30(4), 387-404.

Flap, H. D., \& Völker, B. G. M. (2004). Creation and returns of social capital: Theory, research and measurement. London: Routledge.

Fleming, L., Mingo, S., \& Chen, D. (2007). Collaborative brokerage, generative creativity, and creative success. Administrative Science Quarterly, 52(3), 443-475.

Fleming, L., \& Waguespack, D. (2007). Brokerage, boundary spanning, and leadership in open innovation communities. Organization Science, 18(2), 165-180.

Franke, N., Gruber, M., Harhoff, D., \& Henkel, J. (2006). What you are is what you like-similarity biases in venture capitalists' evaluations of start-up teams. Journal of Business Venturing, 21(6), 802-826.

Granovetter, M. (1985). Economic-action and social-structure-the problem of embeddedness. American Journal of Sociology, 91(3), 481-510.

Granovetter, M. (1992). Problems of explanation in economic sociology. In N. Nohria \& R. G. Eccles (Eds.), Networks and organizations: Structure, form, and action (pp. 25-56). Boston: Harvard Business School Press.
Gulati, R. (1995). Does familiarity breed trust? The implications of repeated ties for contractual choice in alliances. Academy of Management Journal, 38(1), 85-112.

Hallen, B. L. (2008). The causes and consequences of the initial network positions of new organizations: From whom do entrepreneurs receive investments? Administrative Science Quarterly, 53(4), 685-718.

Hoang, H., \& Antoncic, B. (2003). Network-based research in entrepreneurship: A critical review. Journal of Business Venturing, 18(2), 165-187.

Hopp, C. (2010). When do venture capitalists collaborate? Evidence on the driving forces of venture capital syndication. Small Business Economics, 35(4), 417-431.

Hsu, D. H. (2004). What do entrepreneurs pay for venture capital affiliation? Journal of Finance, 59(4), 1805-1844.

Hsu, D. H. (2006). Venture capitalists and cooperative start-up commercialization strategy. Management Science, 52(2), 204-219.

Jell, F., Block, J., \& Henkel, J. (2011). Innovativität als Kriterium bei Venture Capital-Investitionsentscheidungen. Kredit und Kapital. (forthcoming).

Jeppesen, L. B., \& Lakhani, K. R. (2010). Marginality and problem-solving effectiveness in broadcast search. Organization Science, 21(5), 1016-1033.

Lerner, J. (1994). The syndication of venture capital investments. Financial Management, 23(3), 16-27.

Lerner, J. (1995). Venture capitalists and the oversight of private firms. Journal of Finance, 50(1), 301-318.

Mendonça, S., Pereira, T. S., \& Godinho, M. M. (2004). Trademarks as an indicator of innovation and industrial change. Research Policy, 33(9), 1385-1404.

Moran, P. (2005). Structural vs. Relational embeddedness: Social capital and managerial performance. Strategic Management Journal, 26(12), 1129-1151.

Nooteboom, B. (2000). Learning and innovation in organizations and economics. Oxford: Oxford University Press.

Ocasio, W. (1997). Towards an attention-based view of the firm. Strategic Management Journal, 18(Summer Special Issue), 187-206.

Poetz, M. K. \& Schreier, M. (2009). Going beyond the obvious: A real-life application of idea generation using analogous market problem solvers. CBS Working Paper. Copenhagen: Copenhagen Business School

Pratch, L. (2005). Value-added investing: A framework for early stage venture capital firms. Journal of Private Equity, 8(3), 13-29.

Reagans, R., \& McEvily, B. (2003). Network structure and knowledge transfer: The effects of cohesion and range. Administrative Science Quarterly, 48(2), 240-267.

Rodan, S., \& Galunic, C. (2004). More than network structure: How knowledge heterogeneity influences managerial performance and innovativeness. Strategic Management Journal, 25, 541-562.

Rowley, T. J., Greve, H. R., Rao, H., Baum, J. A. C., \& Shipilov, A. V. (2005). Time to break up: Social and instrumental antecedents of firm, exits from exchange cliques. Academy of Management Journal, 48(3), 499520.

Sandner, P., \& Block, J. (2011). The market value of R\&D, patents and trademarks. Social Science Research Network. Available at: http://ssrn.com/abstract=1469705. 
Sapienza, H. J., Manigart, S., \& Vermeir, W. (1996). Venture capitalist governance and value added in four countries. Journal of Business Venturing, 11(6), 439-469.

Soda, G. S., Usai, A., \& Zaheer, A. (2004). Network memory: The influence of past and current networks on performance. Academy of Management Journal, 47(6), 893-906.

Sorenson, O., \& Stuart, T. E. (2001). Syndication networks and the spatial distribution of venture capital investments. American Journal of Sociology, 106(6), 1546-1588.

Sorenson, O., \& Stuart, T. E. (2008). Bringing the context back in: Settings and the search for syndicate partners in venture capital investment networks. Administrative Science Quarterly, 53(2), 266-294.

Tyebjee, T. T., \& Bruno, A. V. (1984). A model of venture capitalist investment activity. Management Science, 30(9), 1051-1066.

Uzzi, B. (1997). Social structure and competition in interfirm networks: The paradox of embeddedness. Administrative Science Quarterly, 42(1), 35-67.
Wagner, S., \& Cockburn, I. (2010). Patents and the survival of internet-related ipos. Research Policy, 39(2), 214-228.

Wasserman, S., \& Faust, K. (1994). Social network analysis: Methods and applications. Cambridge, MA: Cambridge University Press.

Wright, M., \& Lockett, A. (2003). The structure and management of alliances: Syndication in the venture capital industry. Journal of Management Studies, 40(8), 2073-2102.

Zaheer, A., \& Bell, G. G. (2005). Benefiting from network position: Firm capabilities, structural holes, and performance. Strategic Management Journal, 26(9), 809-825.

Zhang, J. (2011). The advantage of experienced start-up founders in venture capital acquisition: Evidence from serial entrepreneurs. Small Business Economics, 36(2), 187-208. 